\section{Impact of synbiotic diets including inulin, Bacillus coagulans and Lactobacillus plantarum on intestinal microbiota of rat exposed to cadmium and mercury}

\author{
Dornoush Jafarpour,1 \\ Seyed Shahram Shekarforoush, ${ }^{1}$ \\ Hamid Reza Ghaisari, 1 Saeid Nazifi,2 \\ Javad Sajedianfard 3 \\ Departments of ${ }^{1}$ Food Hygiene and \\ Public Health, 2 Clinical Pathology, \\ 3Physiology, School of Veterinary \\ Medicine, Shiraz University, Iran
}

\section{Abstract}

The aim of this study was to investigate the efficacy of two probiotics and a prebiotic (inulin) on intestinal microbiota of rats exposed to cadmium and mercury. Fifty-four male Wistar rats were randomly divided into nine groups. All groups except control group were fed standard rat chow with $5 \%$ inulin and treated as follows: i) control (standard diet), ii) Lactobacillus plantarum-treated group $\left(1 \times 10^{9} \mathrm{CFU} / \mathrm{day}\right)$, iii) Bacillus coagulans-treated group $\left(1 \times 10^{9}\right.$ spores/day), iv) cadmium-treated group (200 $\mu \mathrm{g} / \mathrm{rat} / \mathrm{day}), \mathrm{v}) L$. plantarum and cadmium-treated group, vi) $B$. coagulans and cadmium-treated group, vii) mercury-treated group (10 $\mu \mathrm{g} / \mathrm{rat} /$ day), viii) $L$. plantarum and mercurytreated group, ix) B. coagulans and mercurytreated group. Cadmium, mercury and probiotics were daily gavaged to individual rats for 42 days. Treatment effects on intestinal microbiota composition of rats were determined. Data showed that cadmium and mercury accumulation in rat intestine affected the gastrointestinal tract and had a reduction effect on all microbial counts (total aerobic bacteria, total anaerobic bacteria, total Lactic acid bacteria, L. plantarum and $B$. coagulans counts) compared to the control group. It was also observed that application of synbiotics in synbiotic and heavy metals-treated groups had a significant effect and increased the number of fecal bacteria compared to the heavy metals groups. Based on our study, it can be concluded that $L$. plantarum and $B$. coagulans along with prebiotic inulin play a role in protection against cadmium and mercury inhibitory effect and have the potential to be a beneficial supplement in rats' diets.

\section{Introduction}

Gastrointestinal microbiota consists of a complex of microorganism species that live in the digestive tracts of human and other mammals. Bacteria make up most of the flora in the colon and up to $60 \%$ of the dry mass of feces. ${ }^{1}$ Bacteria in the gut fulfill a host of useful physiological functions and have a direct impact on human health, including digestion of unutilized energy substrates, ${ }^{2}$ repressing the growth of harmful microorganisms, helping with the production of some vitamins ( $\mathrm{B}$ and $\mathrm{K}$ ), training the immune system to respond only to pathogens and defending against some diseases.3,4 Gut microbiota's balance can be affected through some conditions due to their high sensitivity to physiochemical and environmental factors. These factors consist of antimicrobial agents, disorders of peristalsis, inflammatory bowel diseases, cancer, stress, redox potential, drugs, temperature and nutrients. ${ }^{5}$

Heavy metals are other factors that have toxic effects on the gut ecosystem. Cadmium (Cd) and mercury (Hg) are such heavy metals that have become a major concern for public health. Cd is present at low concentrations in soil, rock and drinking water. ${ }^{6}$ Because of its highly soluble nature compared to other metals, Cd is taken up by plants and is stored in food and feed production. ${ }^{7}$ Dietary exposure to large $\mathrm{Cd}$ doses has been reported to result in adverse health effects in the kidneys, liver, bone, mammary gland, breast, pancreas and colon. ${ }^{8-10}$ Liu et al. ${ }^{11}$ reported that Cd exposure has toxic effects on microbiota of the intestinal tract in mice. $\mathrm{Hg}$ can also be found in air, water and soil. Fish and shellfish are main sources of this toxic element. Hg exposure at high levels can harm the brain, heart, kidneys lungs, and immune system. ${ }^{12,13}$ Many studies investigated how early gut development may be stimulated and overall efficiency of the intestinal microbiota progressed by accumulation of synbiotics (probiotic and prebiotic) with feed. ${ }^{14}$ Lactic acid bacteria (LAB) such as L. acidophilus, L. plantarum and Bifidobacterium are the most claimed probiotics. These probiotics are very sensitive to normal physiological conditions such as the very low $\mathrm{pH}$ of the stomach and bile salts. ${ }^{15,16}$ Hence, a novel beneficial probiotics is introduced that can survive under extreme status. Some strains of $B$. coagulans are able to stand through the gastrointestinal tract and continue their metabolic activities via spore production. ${ }^{17,18}$ Prebiotics are typically non-digestible fibre compounds that pass undigested through the gastrointestinal tract and stimulate the growth and activity of advantageous bacteria like probiotics. ${ }^{19}$ Accordingly, the purpose of the present study is to investigate the influence of two probiotics ( $L$. plantarum and $B$. coagulans) and a prebiotic (inulin) on gut microbiota of rats exposed to $\mathrm{Cd}$ and $\mathrm{Hg}$.
Correspondence: Seyed Shahram Shekarforoush, Department of Food Hygiene and Public Health, School of Veterinary Medicine, Shiraz University, Shiraz, Iran.

Tel.: +98.713.2286950.

E-mail: shekar@shirazu.ac.ir

Key words: Cadmium; mercury; synbiotic diet; gut microbiota.

Acknowledgments: This research was financially supported by "Natural Antimicrobials Centre of Excellence (NACE)" which is gratefully acknowledged. We would like to thank Miss M. Aghazi and Mr. G. Niknia for their technical assistance.

Contributions: the authors contributed equally.

Conflict of interest: the authors declare no potential conflict of interest.

Received for publication: 7 June 2015.

Revision received: 17 July 2015.

Accepted for publication: 29 July 2015.

This work is licensed under a Creative Commons Attribution NonCommercial 3.0 License (CC BYNC 3.0).

(C) Copyright D. Jafarpour et al., 2015

Licensee PAGEPress srl, Italy

Veterinary Science Development 2015; 5:6061

doi:10.4081/vsd.2015.6061

\section{Materials and Methods}

\section{Preparing suspension of probiotic bacteria}

The bacterial strains used in this study were L. plantarum (NCDO 1193) and probiotic strain of $B$. coagulans. Lyophilized L. plantarum CNR273 was obtained from the culture collection of the Department of Food Science and Technology, Shiraz University, Iran and was plated aerobically on the De Man Rogosa Sharpe (MRS) agar (Difco, Detroit, MI, USA) at $37^{\circ} \mathrm{C}$ for $48 \mathrm{~h}$. Then, a single colony was inoculated into $500 \mathrm{ml}$ of MRS broth and incubated at $37^{\circ} \mathrm{C}$ with shaking at $250 \mathrm{rpm}$ for $48 \mathrm{~h}$. The $L$. plantarum pellets were achieved by centrifugation at $3000 \times g$ for $20 \mathrm{~min}$ and washed with sterile normal saline. To determine the viable bacterial cells per ml of suspension, appropriate serial dilution was done and plated in MRS agar. Lyophilized probiotic B. coagulans were donated by the Pardis Roshd Mehregan Company, Iran. Spore suspension of the bacterium $\left(1 \times 10^{9}\right.$ spore/mL of sterile saline) was prepared according to the method of Abhari et al. ${ }^{20}$ 


\section{Preparation of rat diets}

The experimental diets were based on the standard diets for rats plus 5\% chicory based inulin (Roosendaal, The Netherlands) and contained $24.5 \%$ protein, $6.2 \%$ ash, $52.2 \%$ starch, $6.6 \%$ sugar, $6.5 \%$ fat and $4 \%$ moisture. Regarding micronutrients, the rat chow contained $0.72 \%$ calcium, $0.6 \%$ phosphorus, $0.25 \%$ chloride and $0.23 \%$ magnesium among others. The inulin content in the rat's diet was calculated based on food intake. The food intake of each rat with mean of $200 \mathrm{~g}$ body weight is 10 $\mathrm{g} /$ day, so feedstuff was mixed with $5 \%$ inulin; it means each rat received $0.5 \mathrm{~g}$ inulin/day.

\section{Preparation of heavy metal solu- tions}

The preparation of $\mathrm{Cd}$ and $\mathrm{Hg}$ solutions was done according to the method of Nwokocha $e t$ al.21 The $\mathrm{CdCl}_{2}$ (Merck, Darmstadt, Germany) solution $(200 \mu \mathrm{g} / \mathrm{mL})$ was administered continuously at a dose of $200 \mu \mathrm{g} / \mathrm{rat} / \mathrm{day}$. The $\mathrm{HgCl}_{2}$ (Merck) solution $(10 \mu \mathrm{g} / \mathrm{mL})$ was performed continuously at a dose of $10 \mu \mathrm{g} / \mathrm{rat} / \mathrm{day}$. Both metals were fed to each rat using a special gavage needle.

\section{Animals and treatment}

Fifty-four male Wistar rats weighing $170 \pm 10$ $\mathrm{g}$ were purchased from the Razi Vaccine and Serum Research Institute, Shiraz, Iran. Rats were kept in stainless steel cages under standardized conditions at temperature of $23 \pm 2^{\circ} \mathrm{C}$, relative humidity of $60 \pm 5 \%$ and exposure to a $12 \mathrm{~h}$ light/dark cycle with ad libitum access to diet and tap water.

After an acclimatization period of 1 week, as shown in detail in Table 1, the animals were randomly divided into nine groups ( $n=6 /$ group) and treated for 42 days. All the experimental procedures were done following the ethical guidelines of the animal welfare (approved by Shiraz University animal welfare laws, guidelines and policies in Iran).

\section{Culturing of fecal microbiota}

Fresh fecal samples were collected from each rat on two mentioned days of the experimental period (21 and 42$)$ by gently handling their tails to induce defecation. Then, samples were immediately brought to the laboratory, accurately weighed and diluted in a ratio of 9:1 with sterile saline. After homogenizing for $90 \mathrm{~s}$ using a stomacher (Model BA6021, Steward Lab., UK), specimens were diluted in 10-fold dilution solution (saline) to count the bacterial load.

\section{Total aerobic bacteria count}

Plate count agar (PCA, Merck, Germany) was used for detection of total aerobic bacterial. Plates were incubated aerobically at $37^{\circ} \mathrm{C}$ for $24 \mathrm{~h}$.
Table 1. Treatment groups used in the experimental study.

\begin{tabular}{lll} 
Treatment groups & Feeding & Gavaging $(1 \mathrm{~mL}$ volume, once daily $)$ \\
Control & Standard diet & Normal saline \\
$\mathrm{Lp}$ & Standard diet $+5 \%$ inulin & L. plantarum $\left(1 \times 10^{9} \mathrm{CFU} / \mathrm{mL}\right)$ \\
$\mathrm{Bc}$ & Standard diet $+5 \%$ inulin & B. coagulans $\left(1 \times 10^{9} \mathrm{spore} / \mathrm{mL}\right)$ \\
$\mathrm{Cd}$ & Standard diet $+5 \%$ inulin & Cadmium $(200 \mathrm{mg} / \mathrm{L})$ \\
\hline $\mathrm{Lp}+\mathrm{Cd}$ & Standard diet $+5 \%$ inulin & Cadmium + L. plantarum \\
$\mathrm{Bc}+\mathrm{Cd}$ & Standard diet $+5 \%$ inulin & Cadmium + B. coagulans \\
\hline $\mathrm{Hg}$ & Standard diet $+5 \%$ inulin & Mercury $(10 \mathrm{mg} / \mathrm{L})$ \\
$\mathrm{Lp}+\mathrm{Hg}$ & Standard diet $+5 \%$ inulin & Mercury + L. plantarum \\
$\mathrm{Bc}+\mathrm{Hg}$ & Standard diet $+5 \%$ inulin & Mercury + B. coagulans \\
\hline
\end{tabular}
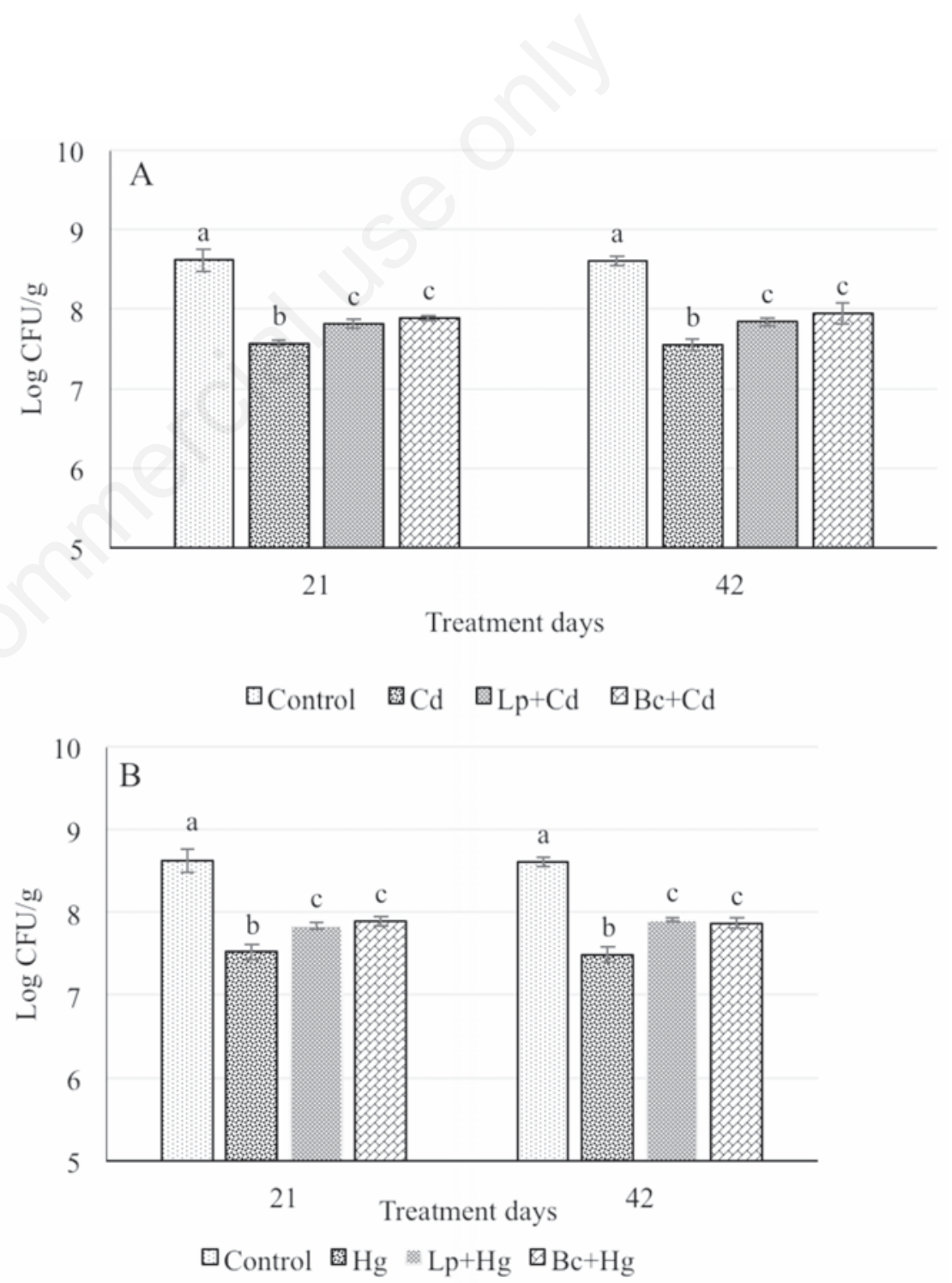

Figure 1. Effect of synbiotic diets on total aerobic count of stool in rats exposed to cadmium (A) and mercury (B). Cd: cadmium, Hg: mercury, Lp: L. plantarum, Bc: B. coagulans. The different letters indicate statistically significant differences between groups in each day of sampling $(P<0.05)$. 


\section{Total anaerobic bacteria count}

Total anaerobic bacteria were counted on PCA with anaerobic condition (Anaerocult $\mathrm{A}^{\circledR}$, Merck, Germany). Incubation was done at $37^{\circ} \mathrm{C}$ for $24 \mathrm{~h}$.

\section{Total lactic acid bacteria count}

MRS agar was used for the enumeration of total LAB. All plates were aerobically incubated at $37^{\circ} \mathrm{C}$ for $48 \mathrm{~h}$.

\section{Lactobacillus plantarum count}

The number of $L$. plantarum was determined by applying appropriate dilutions on the MRS agar supplemented with $4 \mathrm{mg} / \mathrm{L}$ ciprofloxacin (Sigma, USA). The plates were aerobically incubated at $37^{\circ} \mathrm{C}$ for $48 \mathrm{~h}$.

\section{Bacillus coagulans count}

NYSM agar $(0.5 \% \mathrm{NaCl}, 0.5 \%$ pepton, $0.3 \%$ beef extract, $0.05 \%$ yeast extract, $0.01 \% \mathrm{CaCl}_{2}$, $0.02 \% \mathrm{MgCl}_{2}, 0.001 \% \mathrm{MnCl}_{2}, 1 \%$ glucose and $1.5 \%$ agar) was used for the enumeration of $B$. coagulans. NYSM agar plates were aerobically incubated at $37^{\circ} \mathrm{C}$ for $24 \mathrm{~h}$.

\section{Statistical analysis}

The results are expressed as mean \pm SD . Statistical analysis for significant differences among group means was tested by one-way analysis of variance (ANOVA), followed by Duncan's post hoc test with the help of a software SPSS 16.0 windows. $\mathrm{P}<0.05$ was considered significance level.

\section{Results}

Figure 1 shows the effect of synbiotic diet (probiotic and prebiotic) on total aerobic counts in rats exposed to $\mathrm{Cd}$ and $\mathrm{Hg}$. The number of Log Total Aerobic Count (TAC) in the control group was $8.61 \mathrm{CFU} / \mathrm{g}$. $\mathrm{Cd}$ and $\mathrm{Hg}$ significantly decrease the total aerobic bacteria both in day 21 and 42 of sampling. Addition of synbiotic in heavy metal groups caused changes in Log TVC level. The results showed that feeding two probiotics, $L$. plantarum and B. coagulans to $\mathrm{Cd}$ and $\mathrm{Hg}$ - treated rats significantly $(\mathrm{P}<0.05)$ increased the total aerobic counts. For example in $\mathrm{Hg}$ - treated rats the Log TVC at day 42 was $7.49 \mathrm{CFU} / \mathrm{g}$ but applying $L$. plantarum increased the Log TVC to 7.91 CFU/g.

The effect of synbiotic diet (probiotic and prebiotic) on total anaerobic counts in rats exposed to $\mathrm{Cd}$ and $\mathrm{Hg}$ is shown in Figure 2. The number of log total anaerobic count in the control group was $8.84 \mathrm{Log} \mathrm{CFU} / \mathrm{g}$. Consumption of $\mathrm{Cd}$ in treated rats decreased the number to $7.26 \mathrm{CFU} / \mathrm{g}$ and in Hg-treated rats to $7.32 \mathrm{Log} \mathrm{CFU} / \mathrm{g}$. The data indicated that
Table 2. Effect of synbiotic diets on Lactobacillus plantarum count of stool in rats exposed to cadmium and mercury.

\begin{tabular}{lcc} 
Treatments & \multicolumn{2}{c}{ Lactobacillus plantarum count (Log CFU/g) } \\
Control & Day 21 & Day 42 \\
$\mathrm{Lp}$ & $7.26 \pm 0.02^{\mathrm{a}}$ & $6.93 \pm 0.15^{\mathrm{a}}$ \\
$\mathrm{Cd}$ & $8.17 \pm 0.06^{\mathrm{b}}$ & $7.90 \pm 0.04^{\mathrm{b}}$ \\
$\mathrm{Lp}+\mathrm{Cd}$ & $4.82 \pm 0.10^{\mathrm{c}}$ & $4.37 \pm 0.06^{\mathrm{c}}$ \\
$\mathrm{Hg}$ & $7.26 \pm 0.10^{\mathrm{a}}$ & $7.22 \pm 0.05^{\mathrm{d}}$ \\
$\mathrm{Lp}+\mathrm{Hg}$ & $5.01 \pm 0.01^{\mathrm{d}}$ & $5.06 \pm 0.09 \mathrm{e}$ \\
$\mathrm{Le}$ & $7.30 \pm 0.06^{\mathrm{a}}$ & $7.39 \pm 0.02^{\mathrm{d}}$ \\
\hline
\end{tabular}

Results are mean \pm SD. Lp: L. plantarum, Cd: cadmium, Hg: mercury. Different letters indicate significant differences between treatments $(\mathrm{P}<0.05)$

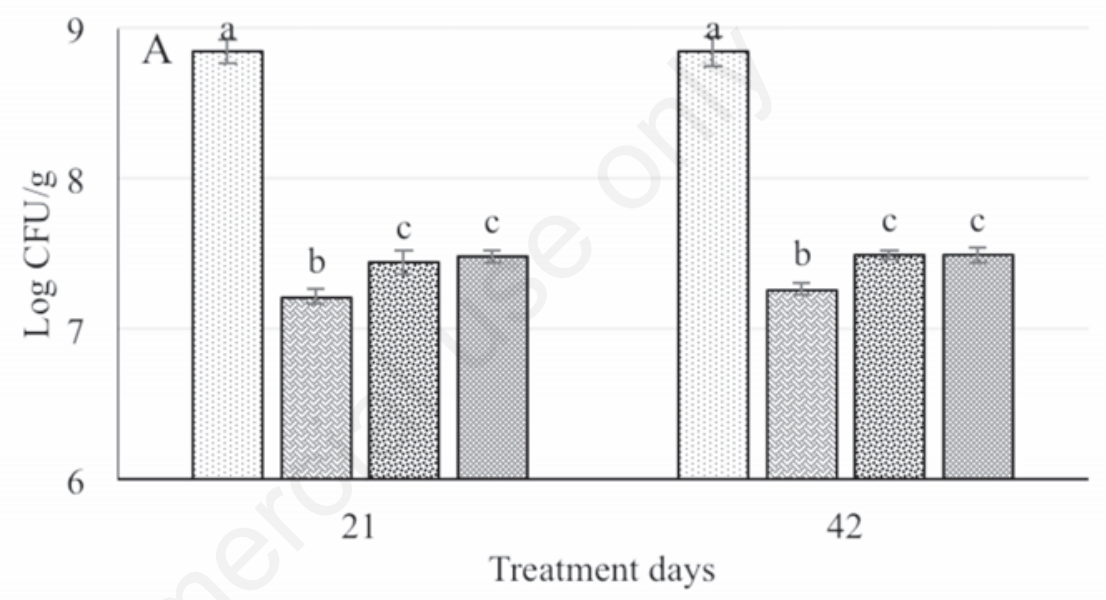

$\square$ Control $\quad \square_{\mathrm{Cd}} \quad$ 总 $\mathrm{Lp}+\mathrm{Cd} \quad \square_{\mathrm{Bc}+\mathrm{Cd}}$

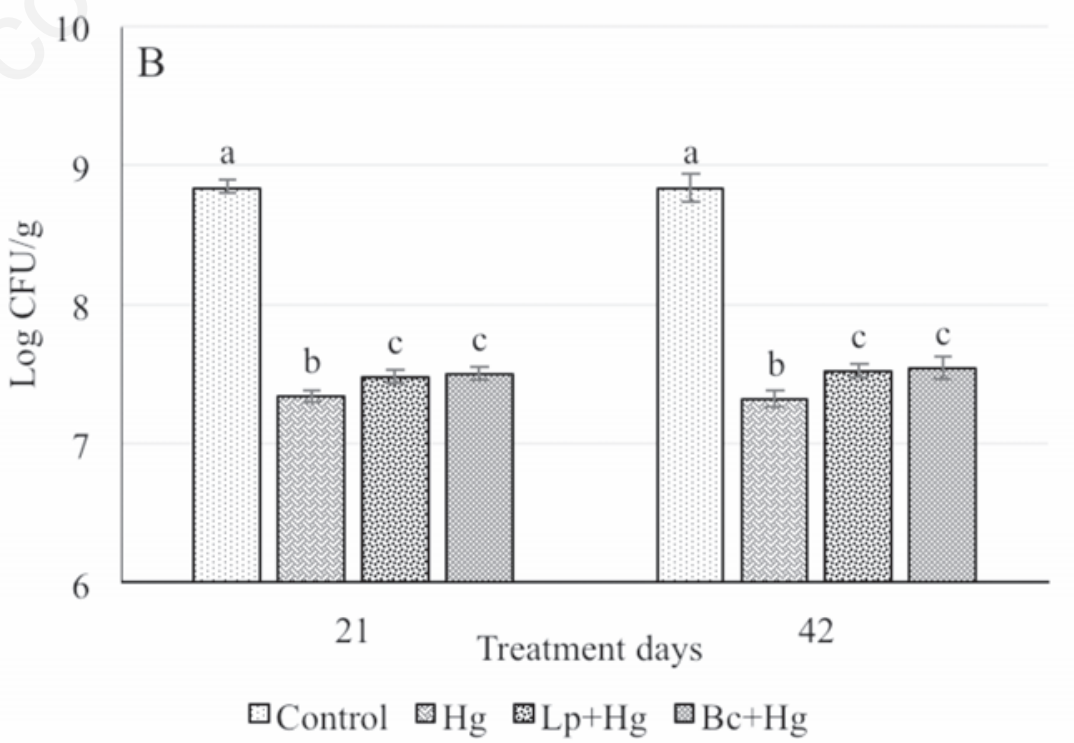

Figure 2. Effect of synbiotic diets on total anaerobic count of stool in rats exposed to cadmium (A) and mercury (B). Cd: cadmium, Hg: mercury, Lp: L. plantarum, Bc: B. coagulans. The different letters indicate statistically significant differences between groups in each day of sampling $(\mathbf{P}<0.05)$. 
Cd and $\mathrm{Hg}$ significantly $(\mathrm{P}<0.05)$ decreased the total anaerobic bacteria both in day 21 and 42 of sampling. Also, our data indicated that usage of probiotics significantly $(\mathrm{P}<0.05)$ affected the anaerobic count and increased the number of bacteria from 7.32 Log CFU/g to 7.54 Log CFU/g.

Figure 3 represents the effect of synbiotic diet (probiotic and prebiotic) on Lactic Acid Bacteria (LAB) count of stool in rats exposed to $\mathrm{Cd}$ and $\mathrm{Hg}$. Data showed that there was significant change in LAB counts in heavy metal groups compared with control group which caused reduction in the LAB microbiota population from $8.83 \mathrm{Log} \mathrm{CFU} / \mathrm{g}$ to $7.16 \mathrm{Log} \mathrm{CFU} / \mathrm{g}$. Both $\mathrm{Cd}$ and $\mathrm{Hg}$ significantly decreased the total LAB in day 21 and 42 of sampling. The presence of probiotics in heavy metal treatedrat diets significantly affected the total LAB and increased the population to $8.77 \mathrm{Log} \mathrm{CFU} / \mathrm{g}$ compared with heavy metal group. Both $L$. plantarum and $B$. coagulans produced an equal effect on total LAB counts. Statistically significant differences were observed for the count of L. plantarum in heavy metals-treated groups and synbiotic groups (Table 2). Prescription of $L$. plantarum in rat diets caused significant increase $(\mathrm{P}<0.05)$ in the L. plantarum populations in rat intestine and faeces in day 21 and 42 of sampling that the number of the bacterium from 7.26 and $6.93 \mathrm{Log}$ CFU/g in control group increased to 8.17 and $7.90 \mathrm{Log} \mathrm{CFU} / \mathrm{g}$ in L. plantarum group, respectively. $\mathrm{Cd}$ and $\mathrm{Hg}$ significantly decreased the $L$. plantarum count in rats that did not receive this bacteria both in day 21 and 42 of sampling. Particularly, feeding L. plantarum in $\mathrm{Cd}$ and $\mathrm{Hg}$ treated groups cause significant increase in $L$. plantarum count (Table 2).

Table 3 shows the effect of synbiotic supplement on $B$. coagulans count of stool in rats exposed to $\mathrm{Cd}$ and $\mathrm{Hg}$. The data revealed that application of $B$. coagulans in rat diets caused significant increase $(\mathrm{P}<0.05)$ in the $B$. coagulans populations in rat stool in day 21 and 42 of sampling that the number of $B$. coagulans from 4.47 Log CFU/g in control group increased to 7.36 and $7.84 \mathrm{Log} \mathrm{CFU} / \mathrm{g}$ in B. coagulans group, respectively. $\mathrm{Cd}$ and $\mathrm{Hg}$ significantly decreased the $B$. coagulans count in rats that did not receive this bacteria both in day 21 and 42 of sampling. Feeding B. coagulans in $\mathrm{Cd}$ and $\mathrm{Hg}$ treated groups cause significant increase in $B$. coagulans count that raise the number (Table 3 ).

\section{Discussion}

The heavy metals poisoning has become a major concern in industrialized countries. Here, a murine model was used to examine the effect of synbiotic supplementation on the intestinal microbiota of rats that had been poi-
Table 3. Effect of synbiotic diets on Bacillus coagulans count of stool in rats exposed to cadmium and mercury.

\begin{tabular}{lcc} 
Treatments & \multicolumn{3}{c}{ Bacillus coagulans count $(\mathrm{Log}$ CFU/g) } \\
\hline Control & Day 21 & Day 42 \\
$\mathrm{Lp}$ & $4.47 \pm 0.07 \mathrm{a}$ & $4.47 \pm 0.10^{\mathrm{a}}$ \\
$\mathrm{Cd}$ & $7.36 \pm 0.04^{\mathrm{b}}$ & $7.84 \pm 0.07^{\mathrm{b}}$ \\
$\mathrm{Lp}+\mathrm{Cd}$ & $2.45 \pm 0.30 \mathrm{c}$ & $2.41 \pm 0.25^{\mathrm{c}}$ \\
$\mathrm{Hg}$ & $5.49 \pm 0.06^{\mathrm{d}}$ & $5.40 \pm 0.03^{\mathrm{d}}$ \\
$\mathrm{Lp}+\mathrm{Hg}$ & $2.63 \pm 0.11 \mathrm{c}$ & $2.55 \pm 0.14 \mathrm{c}$ \\
\hline
\end{tabular}

Results are mean \pm SD. Bc: B. coagulans, Cd: cadmium, Hg: mercury.Different letters indicate significant differences between treatments $(\mathrm{P}<0.05)$

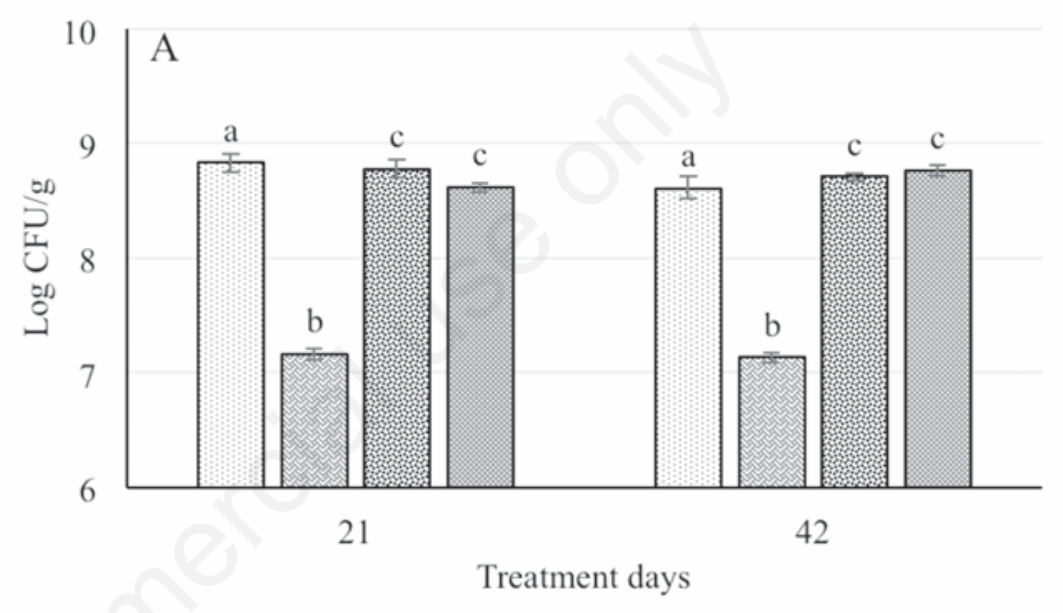

$\square$ Control $\square_{\mathrm{Cd}} \operatorname{arp}_{\mathrm{Lp}+\mathrm{Cd}} \square_{\mathrm{Bc}+\mathrm{Cd}}$

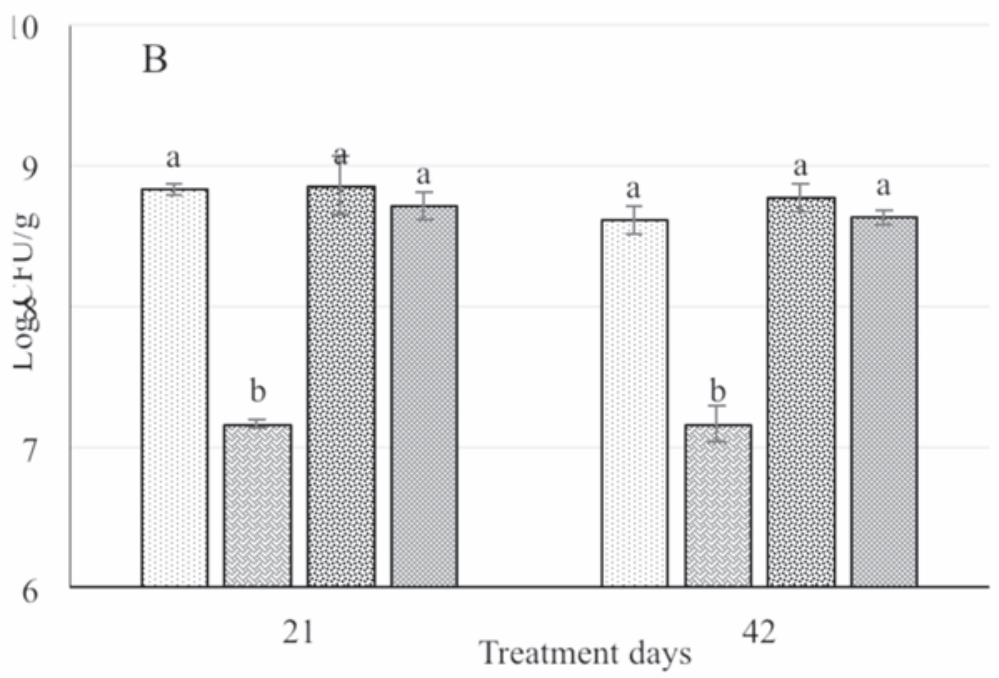

$\square_{\text {Control }} \square_{\mathrm{Hg}} \quad$ 然p+Hg $\quad \square_{\mathrm{Bc}+\mathrm{Hg}}$

Figure 3. Effect of synbiotic diets on lactic acid bacteria count of stool in rats exposed to cadmium (A) and mercury (B). Cd: cadmium, Hg: mercury, Lp: L. plantarum, Bc: B. coagulans. The different letters indicate statistically significant differences between groups in each day of sampling $(\mathbf{P}<0.05)$. 
soned with two heavy metals, cadmium and mercury. In this study, we focused on the microbiota and its response to host consumption of $\mathrm{Cd}$ and $\mathrm{Hg}$ along with synbiotic supplement.

Two probiotic bacteria (B. coagulans and $L$. plantarum) and prebiotic (inulin) were applied as synbiotic diets. It was observed that cadmium and mercury accumulation in rat intestine affected the gastrointestinal tract and impaired the gut barrier. Diets containing heavy metals (Cd or $\mathrm{Hg}$ ) were investigated to determine whether they have a reduction effect on all microbial counts in treated groups. Many reports indicated that heavy metals (Cd, Zn, Cs) have an inhibitory effect on bacteria by delaying the initiation of bacterial growth and inhibiting their growth. ${ }^{22-24}$ Ghorbani et al.25 expressed that sufficient metal exposure will result in immediate death of microorganisms due to disruption of essential functions, and to more gradual changes in population sizes due to changes in viability or competitive ability. Probiotic bacteria B. coagulans and $L$. plantarum received significant stress from the two mentioned heavy metals (Cd and $\mathrm{Hg}$ ) compared to the non-exposed groups. Our result is confirmed by the report of Liu et al. 11 that $\mathrm{Cd}$ treatment could decrease the population of gut bacteria and the thickness of mice inner mucus layer was also attenuated by $\mathrm{Cd}$ treatment.

In contrast, it was found that in treated synbiotic + heavy metals groups the microbial counts were not so reduced compared with heavy metals groups. It seems that when the number of bacteria is low the heavy metals affect them, but in synbiotic + heavy metals groups by increasing the probiotic bacteria heavy metals' effect is reduced. In recent years studies have demonstrated that some bacteria such as probiotics have the largest role in binding metals, preventing their entry to the body and, thus, protecting the host. ${ }^{26,27}$ It was found that inulin and probiotics had a considerable effect on fecal microbiota. According to Van Heugten et al. ${ }^{28}$ dietary supplement with probiotics can potentially alter gut microbiota by selectively stimulating the growth of beneficial bacteria while suppressing the growth of pathogenic bacteria. Also, Lin et al. ${ }^{29}$ reported that the use of probiotics in the feed enhanced Lactobacillus number and reduced $E$. coli population indicating that dietary supplements are efficient to improve broiler intestinal microbiota balance.

Moreover, the utilization of inulin in rat diet as a prebiotic ingredient demonstrated a remarkable effect on the ecosystem of intestinal tract by increasing the total lactic acid bacteria population in rats. This result is supported by the report of Roberfroid that fermented nondigestible food ingredients, such as inulin, beneficially affect the host by selectively stim- ulating the growth and/or activity of one or a limited number of bacteria in the colon by acting as substrate for them. ${ }^{30}$

\section{Conclusions}

In conclusion, this study provided substantial insight in illustrating the inhibitory effect of cadmium and mercury and the impact of synbiotic to rat gut microbiota. This work reveals the potential of synbiotics to decrease the cadmium and mercury repressive effect on the population of gut bacteria.

These interesting findings demonstrate that since $B$. coagulans and $L$. plantarum have the potential to supply the gut microbiota to the normal condition in $\mathrm{Cd}$ and $\mathrm{Hg}$ treated rats, it can be used as a supplementary component in treatment diets.

\section{References}

1. Scott KP, Gratz SW, Sheridan PO, et al. The influence of diet on the gut microbiota. Pharmacol Res 2013;69:52-60.

2. Wynne AG, McCartney AL, Brostoff J, et al. An in vitro assessment of the effects of broad-spectrum antibiotics on the human gut microflora and concomitant isolation of a Lactobacillus plantarum with antiCandida activities. Anaerobe 2004;10:1659.

3. Guarner F, Malagelada J. Gut flora in health and disease. Lancet 2003;361:512-9.

4. Sears CL. A dynamic partnership: celebrating our gut flora. Anaerobe 2005;11:24751.

5. Heavey P, Rowland I. The gut microflora of the developing infant: microbiology and metabolism. Microbiol Ecol Health Dis 1999;11:75-83.

6. Jarup L. Hazards of heavy metal contamination. Br Med Bull 2003;68:167-82.

7. Sarwar N, Malhi SS, Zia MH, et al. Role of mineral nutrition in minimizing cadmium accumulation by plants. J Sci Food Agric 2010;90:925-37.

8. Nordberg GF, Jin T, Wu X, et al. Prevalence of kidney dysfunction in humans - relationship to cadmium dose, metallothionin, immunological and metabolic factors. Biochemie 2009;91:1282-5.

9. Satarug S, Garrett SH, Sens MA, Sens DA. Cadmium, environmental exposure, and health outcomes. Environ Health Perspect 2010;118:182-90.

10. Waalkes MP. Cadmium carcinogenesis in review. J Inorgan Biochem 2000;79:241-4.

11. Liu Y, Li Y, Liu K, Shen J. Exposing to cadmium stress cause profound toxic effect on microbiota of the mice intestinal tract. PLOS One 2014;9:e85323.

12. Clarkson TW, Magos L, Myers GJ. The toxicology of mercury: current exposures and clinical manifestations. N Engl J Med 2003;349:1731-7.

13. Houston MC. The role of mercury and cadmium heavy metals in vascular disease, hypertension, coronary heart disease, and myocardial infarction. Altern Ther Health Med 2007;13:S128-33.

14. Yang SC, Chen JY, Shang HF, et al. Effect of synbiotics on intestinal microflora and digestive enzyme activities in rats. World $\mathrm{J}$ Gastroenterol 2005;11:7413-7.

15. Bezkorovainy A. Probiotics: determinants of survival and growth in the gut. Am J Clin Nutr 2001;73:399S-405S.

16. Holzapfel WH, Haberer P, Snel J, et al. Overview of gut flora and probiotics. Int $\mathrm{J}$ Food Microbiol 1998;41:85-101.

17. Hyronimus B. Acid and bile tolerance of spore-forming lactic acid bacteria. Int $\mathrm{J}$ Food Microbiol 2000;61:193-7.

18. Katsutoshi AR. Effect spore-bearing lactic acid-forming bacteria (Bacillus coagulans SANK 70258) administration on the intestinal environment, defecation frequency, faecal characteristics and dermal characteristics in humans and rats. Microbiol Ecol Health Dis 2003;14:4-13.

19. Gibson GR, Roberfroid MB. Dietary modulation of the human colonic microbiota: introducing the concept of prebiotics. J Nutr 1995;125:1401-12.

20. Abhari KH, Shekarforoush SS, Sajedianfard J, et al. The effects of prebiotic, probiotic and synbiotic diets including Bacillus coagulans and inulin on rat intestinal microbiota. Iranian J Vet Res. 2015; In Press.

21. Nwokocha CR, Owu DU, Nwokocha MI, et al. Comparative study on the efficacy of Allium sativum (garlic) in reducing some heavy metal accumulation in liver of Wistar rats. Food Chem Toxicol 2012;50:222-6.

22. Gikas P, Şengör SS, Ginn TR, et al. The effects of heavy metals and temperature on microbial growth and lag. Global Nest J 2009;1:325-32.

23. Şengör SS, Barua S, Gikas P, et al. Influence of heavy metals on microbial growth kinetics including lag time: mathematical modeling and experimental verification. Environ Toxicol Chem 2009;28:2020-9.

24. Şengör SS, Gikas $P$. The influence of single and combined effects of $\mathrm{Zn}, \mathrm{Cu}$ and temperature on microbial growth. Global Nest J 2014;16:699-706.

25. Ghorbani, NR, Salehrastin, N, Moeini, A. Heavy metals affect the microbial populations and their activities, in 
Symposium of 17th WCSS, 14-21 August, Thailand. 2002; 2234-2245.

26. Bhakta JN, Ohnishi K, Munekage Y, et al. Characterization of lactic acid bacteriabased probiotics as potential heavy metal sorbents. J Appl Microbiol 2012;112:1193206.

27. Ibrahim F, Halttunen T, Tahvonen R, Salminen S. Probiotic bacteria as potential detoxification tools: assessing their heavy metal binding isotherms. Canadian J Microbiol 2006;52:877-85.

28. Van Heugten E, Funderburke DW, Dorton KL. Growth performance, nutrient digestibility, and fecal microflora in weanling pigs fed live yeast. J Anim Sci 2003;81:1004-12.

29. Lin SY, Hung ATY, Lu JJ. Effects of supple- ment with different level of Bacillus coagulans as probiotic on growth performance and intestinal microflora populations of broiler chickens. J Anim Vet Adv 2011;10:111-4.

30. Roberfroid MB. Prebiotics and probiotics: are they functional foods? Am J Clin Nutr 2000;71:1682S-7S. 